\title{
THE METHOD OF LIVABLE ENVIRONMENTAL EVALUATION BASED ON REMOTE SENSING TECHNOLOGY
}

\author{
Luo Lingjun, Hu yan, He Zong \\ (Chongqing Geomatics Center, The Fourth Floor of No.D ,Neptune Building ,Xinguang Avenue, High-tech \\ Devolopment Zone ,Chongqing New North Zone)
}

KEY WORDS: Human Settlement, Estimation, Integration, Model, Research, Remote Sensing

\begin{abstract}
:
Livable environment is one of the hot topics within the realm of the international research in urban science, and it recently becomes the focus of global governments and city residents. The evaluative content of a livable city came out more earlier in developed country, and got rapid development .Presently, the developed countries have set up one and another representatives of livable city, while China is still in the process of urbanization and industrialization. When we are cheering the tremendous success during the reformation, we should also realize the harm as a result of those achievements to environment .So, a livable city has become the development target by more and more cities. When evaluating a livable city, we should make sure the evaluation indices system .Presently, relevant researches of theory about the evaluation indices from home and aboard are based on economic, society, environment, landscape, culture, safety and so on. Those data are gathered either statistic or through questionnaire and investigate. While livable city is a complex system with biological integrality, just one or two outstanding indices can not show that the residential environment is on a high level .Therefore, the paper sets up the evaluative framework and method of a livable city focusing on remote sensing data. Then discusses how to gather and choose information with RS and GIS technique, confirm the definitions ,quantify all the indices to make them meaningful and comparative .And when we are choosing their indices, we should take account of the way of how to get these data , the method of handling and quantifying those information .The index system based on multi-scale remote sensing information includes contents as follows :traffic density and convenience ,distribution and volume ratio of urban buildings, analysis on the landscape pattern of urban green-space and ecological construction, spatial configuration of urban city ,urban heat effect, monitoring and evaluation of wetland area ,assessment of ecological environment and security, vegetation fraction estimation, distribution of infrastructures, land use and land cover, terrain and physiognomy, geological disaster-prone area analysis, water conservation district, urban open area and so an .And the paper integrates these information with that of non-remote sensing, such as people's identify with the residential environment ,amenity of nature environment, convenience of public establishment, satisfaction of human relations and so on .After analyzing, quantifying and evaluating those data, the paper then brings forward a comprehensive index system .Moreover, the paper presents the comprehensive evaluation model aiming to assess the residential environment of Chongqing city. The model includes a large amount of factors--- factors on remote sensing and other assistant factors coming from statistic data. When building the model ,we should take the consistency and standardization process between different remote sensing data, and between remote sensing data with non-remote sensing data into account, also the independence, representative and importance of these factors. Therefore, we should analyze and evaluate all the factors to make sure the remarkable ones, eliminate redundancy information, and make certain the power of the factors which are used in the model .Thus, the paper sets up the comprehensive evaluation model, and does researches and evaluation on the residential environment . At last the paper puts forward the measures about how to improve human settlements, and give suggestions for the urban planning, reformation and development for a livable city.
\end{abstract}

\section{INTRODUCTION}

In 2005's China City Forum (Beijing Summit), livable city has be regarded as an important part of future regional planning as well as a development target. Therefore, livable city has become a new focus in chinese urban development , and it has aroused extensive attention from all sectors of society, government, media, academics and the public research.

Livable city is one of the goals about the future development of Chongqing. Recent 20 years till the next several decades is the high-speed development period of Chongqing, during this time there could be a large number of urban population influx. With large numbers of people quickly gathered in, the ecological environment, pollution, energy shortages, traffic congestion, housing problem and other issues will come out as follows. Undoubtedly, it puts forwards a higher demand to the construction of urban settlements, and "livable Chongqing" is generated under this background.
The study about livable city first originated from the houseing problem during the first industrial revolutionin period in Western developed countries. After the Second World War, it paids more attention to the pursuits of comfortable and pleasant. Then, From the 1970s bringing forward the needs to natural ecological health and human ecological, and the emergence and growth of new urbanism theory in the 1980s, to the smart growth theory and it continuation in the 1990s, the theories of livable city have gained development of several decades , and foreign countries have created one and another apotheosis of livable city. While domestic study on livable environment began in the $1990 \mathrm{~s}$, and is still at the initial stage. The concept, standards and understanding about the livable environment study in china is different at the present time, the practice emphasizes on diverse aspects. The paper systematically does research on study about livable environment both home and abroad, investigates the representative characteristic of the environmental habitat and features of urban development in Chongqing, gives full play to remote sensing technology in data access and analysis in those fields such as hydrology, climate, 
culture, environment, urban planning and so on, then puts forward the multi-scale livable environment index system, finally evaluates the living environment, which is of theoretical and practical significance. The results will provide basic support and reference to government management and urban planning, and it is of far-reaching significance to enhance the quality of urban construction, meet people's growing demand for livable environment, promote the city's sustainable development.

\section{EVALUATION INDEX SYSTEM BASED ON MULTI-SCALE REMOTE SENSING INFORMATION}

\subsection{Evaluation Scale and Unit}

The research and evaluation of livable city has three scales ${ }^{(1)}$, the first is the urban scale, that is between city and cities, to study the city as an independent unit, content and the corresponding evaluation indices are relatively macroscopical; the second is within the city, to study different blocks, communities or certain grid $(500 \mathrm{~m} \times 500 \mathrm{~m}$ or $1 \mathrm{~km} \times 1 \mathrm{~km})$ as an independent evaluation unit, content and the corresponding evaluation indices are relatively specific ; the third is the residential scale, to study the independent residential area or buildings, content and indicators are more micro. This paper studys the livable environment in the second scale. Clearly, the livable environment evaluation of the internal structure and space in inner city, is of great theoretical and practical significance to urban environmental reasearch and urban planning, therefore, the evaluation unit is the 454 functional units within the urban planning area of Chongqing. These functional units are mutual independent urban living space. They are not only a combination of different architectural features in geographical space, but also social space integration systems of people living activities. The definition of those functional units may be: a certain scale of constructions with outdoor greenland and kinds of public facilities,through certain types of barriers with the outside apart such as roads, buildings and so on, architectures and other landscape in the region having some common features. In other words, the residential area is a cluster complex with living, social, economic and ecological functions, and its scope is not fixed, the smallest is $0.16 \mathrm{~km}^{2}$, the largest is $15.4 \mathrm{~km}^{2}$.

\subsection{Livable Environment Evaluation Index System}

Livable environment is a complex system of people, environment, society, economy, culture, climate, security and so on. The research of livable environment evaluation indices domestic carried out in 2000 gradually $^{(2)}$, but they are still some traditional urban environment indices, and have not taken full advantage of the rapidly developed remote sensing technique and satellite images, resulting the origin of those indices are excessive dependence on questionnaire and survey, and increased the difficulty in practical application. This paper puts forward the livable environment evaluation index system(Table 1) based on multi-scale remote sensing information, and gives full play to remote sensing technology in data access and analysis in these filed as hydrology, climate, culture, environment, urban planning and so on. In table 1, the black-rough fonts indicate that these indices can be extracted from remote sensing data or from geo-spatial information, the others are statistical information or through questionnaire. Those questionnaire data can be included in evaluation model,and on the other hand,they could be verification of the results.

Among these indices, the green space,including green coverage, green open space distribution and landscape pattern analysis, mainly through high-resolution satellite images (QuickBird); water and wetland, including the distribution,the impact of water and wetland, water quality and water color monitoring, and industrial wastewater discharge and pollution, mainly through mid and high resolution satellite images (QuickBird, $\mathrm{TM}$ and Cebers); atmospheric environment, including the exhaust,toxic and harmful gas emission of factories and enterprises(through aerial images), the distribution of ozone (O3), $\mathrm{CO} 2, \mathrm{SO} 2$, methane (CH4), as well as aerosol and other harmful gases (through TM images and other images); living environment, including the terrain fragmentation and slope of residential area (through DEM); the effect of heat island monitoring(through TM); Shantytowns distribution (through aerial images and geospatial information); building density and rate of capacity(through aerial images and geospatial information); the distribution of solid waste stacking, sewage factory, refuse dump, chemical factory and other polluting enterprises (through high-resolution images and geospatial information); the urban landscape pattern analysis (through high-resolution images).

\section{FACTOR ANALYSIS AND MODELING}

\subsection{Factor Analysis}

The livable environment in inner city is a dynamic, open syntheses, the relationship and the interaction between these internal indices are very complicated.At the same time,the factors and the quality of livable environment is not a simple mapping relationship that is either black or White, with a lot of grey areas. It is difficult to establish a uniform standard.The livable environment itself is of obvious randomness, fuzzy, and relative uncertainty, it is a typical grey system. Therefore,this paper makes use of grey correlation analysis method to deal with the standardization of factors, and also establishs the relationship functions of factors and the living environment. Grey correlation analysis is based on sequence analysis and correlation measure of grey series'geometric similarity, so that to quantify correlation coefficient between different series with a certain series. The higher the correlation coefficient, the more close the sample series to the certain series, which is the basis of comprehensive evaluation.

Steps of grey correlation analysis are as follows:

1. Determine the optimal series (that is, reference series): Select the optimal series;

2. Calculated correlation coefficient (degrees).

Two factors as an example, the first is M1 = (46 88 19 30), the

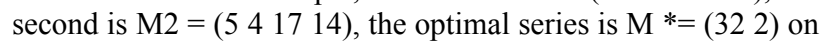
behalf of the M1 and M2 best desirable series.

$$
\zeta_{i k}=\frac{\min _{i} \min _{k}\left|M^{*}{ }_{k}-M^{i}{ }_{k}\right|+\rho \max _{i} \max _{k}\left|\mathrm{M}^{*}{ }_{\mathrm{k}}-\mathrm{M}_{\mathrm{k}}^{\mathrm{i}}\right|}{\left|M^{*}{ }_{k}-M^{i}{ }_{k}\right|+\rho \max _{i} \max _{k}\left|\mathrm{M}_{\mathrm{k}}{ }-\mathrm{M}_{\mathrm{k}}^{\mathrm{i}}\right|}
$$

In this formula, $\zeta_{i k}$ shows the correlation coefficient between the NO. $\mathrm{i}$ data in factors $\mathrm{M}_{\mathrm{k}}$ with the NO.k data in the optimal series; $\rho \in[0.1]$, generally from $0.1-0.5,0.5$ in here. Calculate the correlation coefficients through the above formula,

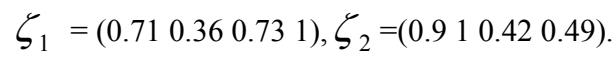




\begin{tabular}{|c|c|c|}
\hline The first level indicators & The second level indicators & The third level indicators \\
\hline \multirow[t]{7}{*}{ Climatic conditions } & \multirow[t]{3}{*}{ temperature } & the average temperature annual \\
\hline & & the days of $\max$ temperature $\geq 35^{\circ} \mathrm{C}$ \\
\hline & & the days of $\min$ temperature $\leq 0^{0} \mathrm{C}$ \\
\hline & precipitation & the average precipitation annual \\
\hline & humidity & the average relative humidity annual \\
\hline & Sunshine hours & the average sunshine hours annual \\
\hline & Special weather & special weather(heavily foggy days) \\
\hline \multirow{2}{*}{$\begin{array}{l}\text { Economic } \\
\text { Income }\end{array}$} & per capita income & \\
\hline & the growth rate of per capita income & \\
\hline \multirow[t]{7}{*}{$\begin{array}{l}\text { Human } \\
\text { Environment }\end{array}$} & $\begin{array}{l}\text { the distribution } \\
\begin{array}{l}\text { reserves,scenic spots, parks, } \\
\text { destinations }\end{array}\end{array}$ & \\
\hline & $\begin{array}{l}\text { the distribution of religious sites and } \\
\text { cultural heritage }\end{array}$ & \\
\hline & $\begin{array}{l}\text { the distribution of community } \\
\text { organizations and public utilities }\end{array}$ & \\
\hline & $\begin{array}{l}\text { the satisfaction of residents to the } \\
\text { community management and support } \\
\text { services }\end{array}$ & \\
\hline & $\begin{array}{l}\text { the satisfaction of residents to the } \\
\text { community environment }\end{array}$ & \\
\hline & $\begin{array}{l}\text { the satisfaction of residents to the } \\
\text { community relations }\end{array}$ & \\
\hline & $\begin{array}{l}\text { the satisfaction of residents to community } \\
\text { landscape }\end{array}$ & \\
\hline \multirow{26}{*}{$\begin{array}{l}\text { Natural } \\
\text { Environment }\end{array}$} & \multirow[t]{6}{*}{ Green space } & Green coverage \\
\hline & & the rate of greenland \\
\hline & & Per capita public green \\
\hline & & Distribution of road greenbelt protection \\
\hline & & Green landscape pattern analysis \\
\hline & & Distribution of green open space \\
\hline & \multirow[t]{6}{*}{ Water and wetland } & Distribution of water \\
\hline & & Distribution of wetlands \\
\hline & & water quality and water color monitoring \\
\hline & & Humidity index \\
\hline & & $\begin{array}{l}\text { industrial wastewater discharge and } \\
\text { pollution }\end{array}$ \\
\hline & & $\begin{array}{l}\text { Evaluation of residents to the sewage } \\
\text { disposal }\end{array}$ \\
\hline & \multirow[t]{5}{*}{ Atmospheric Environment } & $\begin{array}{l}\text { harmful gas emission of factories and } \\
\text { enterprises }\end{array}$ \\
\hline & & $\begin{array}{l}\text { distribution of ozone (O3), } \mathrm{CO} 2, \mathrm{SO} 2, \\
\text { methane (CH4), as well as aerosol and other } \\
\text { harmful gases }\end{array}$ \\
\hline & & $\begin{array}{l}\text { Non-point source pollution index (COD, SO2), } \\
\text { air quality better than or equal to two } \\
\text { standard( days / year) }\end{array}$ \\
\hline & & $\begin{array}{l}\text { evaluation of residents to automobile exhaust } \\
\text { emissions }\end{array}$ \\
\hline & & assessment of Residentst to the air quality \\
\hline & \multirow[t]{9}{*}{ Living environment } & $\begin{array}{l}\text { terrain factor (height difference, slope, } \\
\text { topography fragmentation) }\end{array}$ \\
\hline & & the effect of heat island \\
\hline & & Shantytowns distribution \\
\hline & & building density and rate of capacity \\
\hline & & $\begin{array}{l}\text { landscape pattern analysis of the living } \\
\text { environment }\end{array}$ \\
\hline & & Distribution of open space \\
\hline & & polulation density \\
\hline & & per capita housing area \\
\hline & & survey of solid pollutants \\
\hline
\end{tabular}




\begin{tabular}{|c|c|c|}
\hline & & $\begin{array}{l}\text { distribution of sewage factory, refuse dump, } \\
\text { chemical factory and other polluting } \\
\text { enterprises }\end{array}$ \\
\hline & & noise near the residential area \\
\hline & & $\begin{array}{l}\text { Evaluation of residents to the open-air garbage } \\
\text { spelled }\end{array}$ \\
\hline & & evaluation of residents to the cleanliness \\
\hline $\begin{array}{l}\text { Basis } \\
\text { Facilities }\end{array}$ & $\begin{array}{l}\text { distribution of ducational and cultural } \\
\text { facilities }\end{array}$ & \\
\hline & $\begin{array}{l}\text { distribution of medical and health } \\
\text { facilities }\end{array}$ & \\
\hline & distribution of commercial facilities & \\
\hline & distribution of sports facilities & \\
\hline & Distribution of recreational facilities & \\
\hline & distribution of catering facilities & \\
\hline & distribution of other public facilities & \\
\hline & $\begin{array}{l}\text { satisfaction of residents to commercial } \\
\text { service }\end{array}$ & \\
\hline & $\begin{array}{l}\text { Satisfaction of residents to the quality of } \\
\text { catering services }\end{array}$ & \\
\hline & $\begin{array}{l}\text { satisfaction of residents to recreational } \\
\text { facilities }\end{array}$ & \\
\hline & $\begin{array}{l}\text { satisfactionto educational and cultural } \\
\text { facilities }\end{array}$ & \\
\hline & satisfaction of residents to sports facilities & \\
\hline & $\begin{array}{l}\text { satisfaction of residents to the community } \\
\text { health service }\end{array}$ & \\
\hline & $\begin{array}{l}\text { assessment of residents to water supply } \\
\text { situation }\end{array}$ & \\
\hline & evaluation of residents to gas supply & \\
\hline & $\begin{array}{l}\text { evaluation of residents to normal power } \\
\text { supply }\end{array}$ & \\
\hline Traffic & distribution of all the road & \\
\hline Situation & distribution and the length of bus lines & \\
\hline & per capita road length and area & \\
\hline & mastery of traffic analysis & \\
\hline & $\begin{array}{l}\text { distribution of bus site and light rail } \\
\text { site }\end{array}$ & \\
\hline & $\begin{array}{l}\text { evaluation of residents to the convenience } \\
\text { of city traffic }\end{array}$ & \\
\hline & $\begin{array}{l}\text { assessment of residentsto the city } \\
\text { commuter traffic situation }\end{array}$ & \\
\hline $\begin{array}{l}\text { Public } \\
\text { security }\end{array}$ & \begin{tabular}{lll|}
$\begin{array}{l}\text { Emergency } \\
\text { distribution }\end{array}$ & Evacuation & sites \\
\end{tabular} & \\
\hline & $\begin{array}{l}\text { distribution of geological disasters, } \\
\text { natural disaster-prone areas }\end{array}$ & \\
\hline & distribution of fire and public security & \\
\hline & Backwater flooded areas & \\
\hline & $\begin{array}{l}\text { distribution industrial outlets with } \\
\text { potential safety problems such as gas } \\
\text { stations }\end{array}$ & \\
\hline & $\begin{array}{l}\text { evaluation of residents to the public } \\
\text { security }\end{array}$ & \\
\hline & evaluation of residents to the traffic safety & \\
\hline
\end{tabular}

(the black-rough fonts indicates that these indices can be extracted from remote sensing data or from geo-spatial information, the others are statistical information or through questionnaire.)

Table 1:Livable environment evaluation index system

\subsection{Modeling}

Livable environment is a complex and open system composed of multi-factor in multi-level. There is intricate, inextricably linked to and interaction between the internal system and external environment. Using qualitative and quantitative method to understand and evaluate such complex system, is a very effective evaluation method, that is AHP.

AHP is a method to systematize, model, and quantify the decision-making process of complex phenomenon, therefore, it is also known as multi-level analysis to make sure the weights 
in decision-making. The procedure is divided into the following steps: (1) specific issues; (2) established hierarchy (see table 2); (3) scaling; (4) construction judgement matrix; (5) sort level calculation and consistency test, to determine the weights; (6) evaluation.

In the hierarchy, compare each two factors that subordinates to (or influences) the level above, and compare these factors'importance to the criteria,then quantify factors in accordance with the prescriptive scale to make a matrix, that is, judgement matrix.Data in judgement matrix of various elements are in 1-9 scale in general, mainly through expert assessment or by history (experience) data.

\begin{tabular}{|c|c|}
\hline $\operatorname{Scale}\left(\mathrm{a}_{\mathrm{ij}}\right)$ & meaning \\
\hline 1 & the impact of $C_{i}$ and $C_{j}$ is of the same \\
\hline 3 & $\begin{array}{l}\text { the impact of } C_{i} \text { is a bit stronger than } \\
C_{j}\end{array}$ \\
\hline 5 & the impact of $C_{i}$ is stronger than $C_{i}$ \\
\hline 7 & $\begin{array}{l}\text { the impact of } C_{i} \text { is obviously stronger } \\
\text { than } C_{i}\end{array}$ \\
\hline 9 & $\begin{array}{l}\text { the impact of } C_{i} \text { is absolutely stronger } \\
\text { than } C_{j}\end{array}$ \\
\hline $2,4,6,8$ & is median between above \\
\hline $1,1 / 2, \cdots, 1 / 9$ & on the contrary \\
\hline
\end{tabular}

Table 2:the significance of 1-9 scale

\begin{tabular}{|c|c|c|c|c|c|c|c|}
\hline & $\begin{array}{c}\text { Climatic } \\
\text { conditions }\end{array}$ & $\begin{array}{c}\text { Economic } \\
\text { Income }\end{array}$ & $\begin{array}{c}\text { Human } \\
\text { Environment }\end{array}$ & $\begin{array}{c}\text { Natural } \\
\text { Environment }\end{array}$ & $\begin{array}{c}\text { Basis } \\
\text { Facilities }\end{array}$ & $\begin{array}{c}\text { Traffic } \\
\text { Situation }\end{array}$ & $\begin{array}{c}\text { Public } \\
\text { security }\end{array}$ \\
\hline $\begin{array}{c}\text { Climatic } \\
\text { conditions }\end{array}$ & 1 & $1 / 2$ & $1 / 3$ & $1 / 7$ & $1 / 5$ & $1 / 5$ & $1 / 4$ \\
\hline $\begin{array}{c}\text { Economic } \\
\text { Income }\end{array}$ & 2 & 1 & $1 / 2$ & $1 / 5$ & $1 / 4$ & $1 / 4$ & $1 / 3$ \\
\hline $\begin{array}{c}\text { Human } \\
\text { Environment }\end{array}$ & 3 & 2 & 1 & $1 / 4$ & $1 / 3$ & $1 / 3$ & $1 / 2$ \\
\hline $\begin{array}{c}\text { Natural } \\
\text { Environment }\end{array}$ & 7 & 5 & 4 & 1 & 2 & 2 & 3 \\
\hline $\begin{array}{c}\text { Basis } \\
\text { Facilitie }\end{array}$ & 5 & 4 & 3 & $1 / 2$ & 1 & 1 & 2 \\
\hline $\begin{array}{c}\text { Traffic } \\
\text { Situation }\end{array}$ & 5 & 4 & 3 & $1 / 2$ & 1 & 1 & 2 \\
\hline $\begin{array}{c}\text { Public } \\
\text { security }\end{array}$ & 4 & 3 & 2 & $1 / 3$ & $1 / 2$ & $1 / 2$ & 1 \\
\hline
\end{tabular}

Table 3:judgement matrix of the factors in the first level

Compare each two indicators in the first level according to their effect to the livable environment evaluation ,also consult expert assessment, determine the relative importance and give corresponding scale. Construct the judgement matrix of the factors in the first level as follows(Table 3) :

\section{ANALYSIS AND EVALUATION}

Multiplly all the factors' correlation coefficients by 100 ,make them in the range of 0-100.Caculate the comprehensive livable environment index of the 454 urban functional units ,finding those indices are between 40-82, it shows that the quality of the overrall living environment is not fine.Then sort all the scores to reflect the quality of the living environment descending order.Put the living environment into five categories: very fine(73-82), good(60-73), general (55-60), poor(48-55), and very poor(40-48). The Results map is as follows.

From the map, there is a toatal of 26 very fine units, accounting for $5.7 \%$, mainly located in the center of Yuzhong District, Jiangbei District, Yubei District, Nan'an District, Jiulongpo District, Sha Pingba District. For example, units in Yuzhong District are political center and economic highland, although there the rate of capacity is the highest,green coverage and the rate of greenland is relatively very low, these units are comprehensive entity of trading, finance, information, culture and so on. And there is comprehensive urban functions, kinds of infrastructures, obvious geographical advantages, intensive traffic lines and site, and surrounded by two rivers (Yangtze River and Jialing River), therefore the score is in a high level. Jiangbei District and Yubei District is the hot zone of the most development potential at present, and also the zone the regional planning better implementated. In these units, there is obvious geographical advantages, smooth and convenient traffic; beautiful and clean environment, flat terrain, broad vision, harmonious landscape; a reasonable distribution of open space and green open space, high green coverage,very fine air quality; although kinds of infrastructures have not been able to keep up with the others at present, they still begin to take shape.The very fine units in Shapingba District are located in education and scientific research center, such as Chongqing Normal University, these is beautiful environment, high rate of greenland, and these units are surrounded by kinds of infrastructures 、 tourist destinations、 cultural heritage and so on. Units in Jiulongpo District are distributed in the Daping and Yang Jiaping Area, which is the business central, and indicators of other factors have maintained in a balanced level, therefore the score is also high.

There is a toatal of 44 good units, accounting for $9.7 \%$, around those very fine units. These units are some deputy center,compared with those very fine units,some factors are not so fine ,but they have got a balanced development, so living environment is good.Also,the centre of Beibei District, which is said as garden City,the geographical advantages there are not so obviouse .And centre of Nan'an District, got a relatively 
mature and banlanced development .

Generally speaking, these very fine and good units are in a higher level of urbanization, either regions residential area gathering, political center, economic highland, educational and reasearch centre, trade circle, or regions the urban function and infrastructures developed in a balance.And the proportion of industrial sites (especially heavy industry and polluting enterprises) and shantytowns are relatively low.Around these units, the living environment is just so so, a total of 177 , accounting for $39 \%$. Some units are in a higher level of urbanization, but concentrated by industrial sites and shantytowns, or traffic underdeveloped and less convenient,or region near the airport. More other units are in a low level of urbanization.

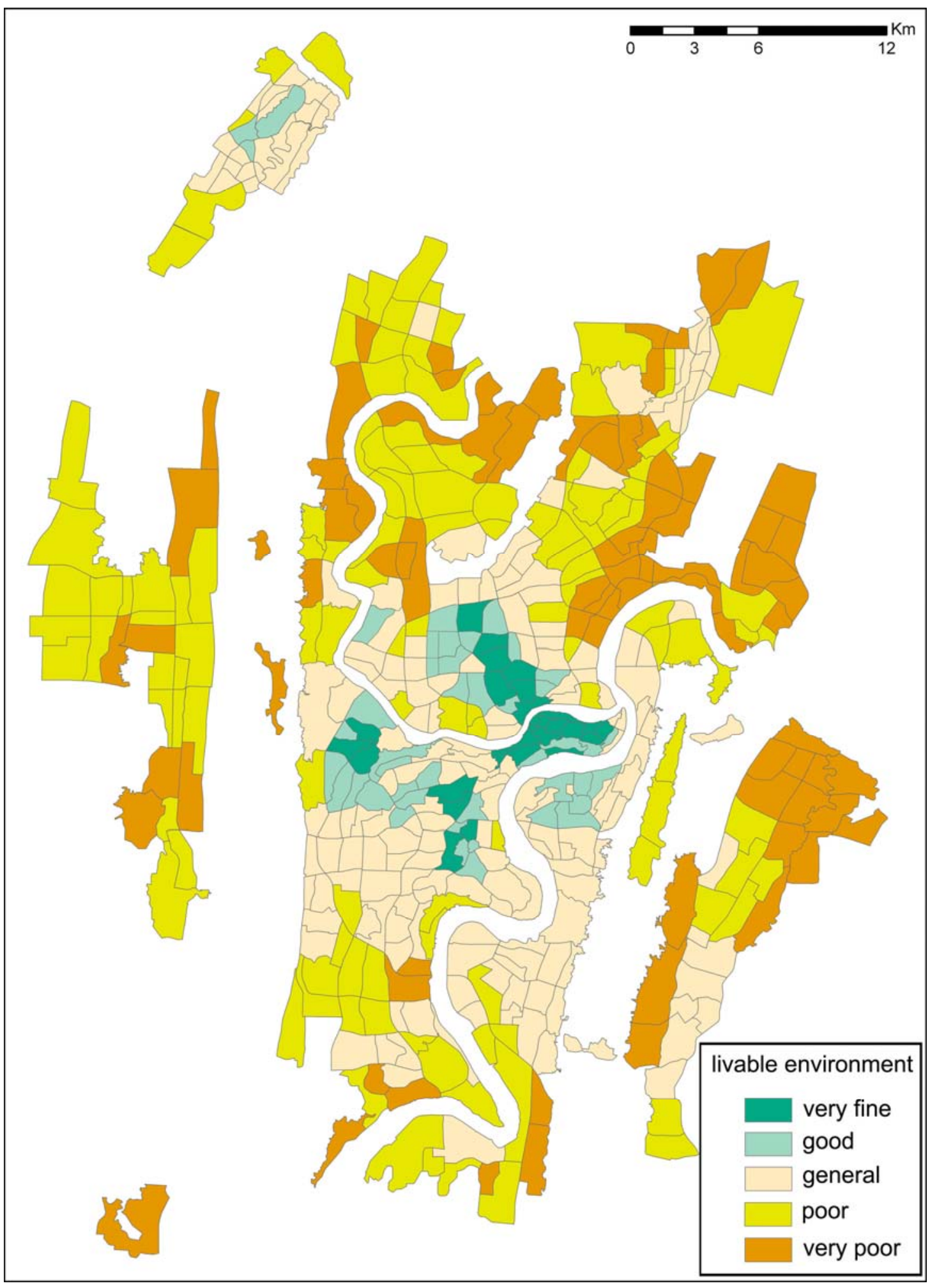

Figure. 1: the evaluation of livable environment of all functional units in planning area of Chongqing 
There is a toatal of 124 poor units, accounting for $27.3 \%$,and a toatal of 83 very poor units, accounting for $18.3 \%$.These units mainly scattered far away the main center of the city, or at some junctions. Some of these units,with flat and relatively little undulating terrain (for example, near the University City), may have a certain development potential and regional advantages,but they are in the ways of being constructed, and the infrastructures have not been built up or made in use. For a long time period, municipal government puts these regions in a secondary position, and investment and construction are far from enough.Low level of economic development and lacking of economic accumulation, seriously restricts the development of all kinds of infrastructures. In addition,little greenland distribution, have not fully met the demand of optimizing the quality of living envrionment, improving regional micro-climat, cleaning up atmospheric environment, and reducing noise. In more units,the geographical advantages is still uncertainty, traffic density is very low,connectivity and mastery is poor,that restricts the economic connection of these areas with the more developed one. There is still huge gap in urban functions ,urban landscape and other infrastructures construction. The practitioners in these region get less education, the proportion of illiterate and semi-literate is higher. Industrial wastes and solid pollutants can not get effective collection and timely cleaning up. What is morefore for those region,is to adjust the industrial structure, develope regional economic, and protect the enviroment at the same time.

\section{OUTLOOK}

RS, GIS and computer technology have been widely used in quantitative research on urban environmental assessment. Using RS technology to acquire and analysis data in hydrology, climate, culture, environment, and urban planning,can overcome the shortcoming that indicators of livable environment evaluation are overly dependent on social statistics questionnaire and surey, making the access of factors practical. It is a low-cost, simple and workable solution. Judging from the current research, further reasearch can be carried out as follows:
1. The evaluation index system still need improvement. Livable environment is a complex system, the index system needs to be further improvement.

2. Evaluation Unit. Urban residential units are the main venue of people in daily life, through the reasearch and evaluation on various environmental indicators, it can provide sufficient reference to urban planning as well as environmental assessment. Although the units in this paper are those urban functional units, they are still of subjectivity.

3. Gray associated analysis is used in this paper, but the optimal series is still open to discussion. And we can also use other methods to analysis and compare those indices.

4. Although AHP is a effective way, it is still rigid slightly for living environment evaluation. The next step,we could consider a variety of methods, to make the livable environment evaluation more reasonable and more accurate.

\section{REFERENCES}

ZHANG Wen-Zhon. Index System and M ethod of Residential Environmental Evaluation in Inner $\mathrm{C}$ ities. SCIENTIA GEOGRAPHICA SINIC, 2007,Vol. 27,No. 1.

CHENG Cheng-qi, LI Qi-qing, SHA Zhi-you, GUO Shi-de.Research on Technology of Environmental Quality Estimation for Urban Flat by Higher Resolution Remote Sensing Imagery. ADVANCES IN EARTH SC IENCE,2006,Vol(21),No.(1)

LI Xue-ming,YANG Bo,JIANG Bin. Human Settlement Quality Assessment of Residential Quarters in the West of Dalian. Journal of Liaoning Normal University (Natural Science Edition,2001,Vol(24),No.3

Wu Liangyong. TheWadev's learned idea and the construction of habitat environmental science [ J ]. City Planning, 1996, ( 1) : 352

Raymond Sterling.Underground Technologies for Livable cities[J].Tunnelling and underground space technology.1997(12),479-490. 
